\title{
Profile of etravirine in the treatment of HIV in pediatrics
}

This article was published in the following Dove Press journal:

Pediatric Health, Medicine and Therapeutics

24 July 2013

Number of times this article has been viewed

\section{Walter Dehority' \\ Rolando MViani²}

'Department of Pediatrics, Division of Infectious Diseases, The University of New Mexico Health Sciences Center, University of New Mexico, Albuquerque, NM, USA; ${ }^{2}$ Department of Pediatrics, Division of Infectious Diseases, Center for AIDS Research, University of California, San Diego School of Medicine, Rady Children's Hospital, San Diego, CA, USA
Correspondence: Rolando M Viani University of California, San Diego School of Medicine, 9500 Gilman Drive, MC 0672, La Jolla, CA 92093-0672, USA

$\mathrm{Tel}+161947 \mid 9177$

Fax + I 85853474 II

Email rviani@ucsd.edu
Abstract: Etravirine is a non-nucleoside reverse transcriptase inhibitor now licensed for treatment of human immunodeficiency virus (HIV)-1 infection in both children over 6 years of age and adults. Etravirine demonstrates a high genetic barrier to the development of resistance, as multiple mutations are typically required prior to the onset of reduced susceptibility to the drug. It retains in vitro and clinical activity against many HIV-1 isolates, demonstrating resistance to other non-nucleoside reverse transcriptase inhibitors, such as efavirenz and nevirapine. Given the ability of HIV to develop resistance rapidly across the non-nucleoside reverse transcriptase inhibitor class of antiretrovirals, etravirine has a welcome place in the management of HIVinfected patients, particularly treatment-experienced individuals harboring non-nucleoside reverse transcriptase inhibitor mutations. Etravirine has been shown to improve CD4 counts and viral load significantly in HIV-infected adults on combination antiretroviral therapy when compared with placebo in a large, randomized controlled trial. Data on the utility of etravirine in children are still somewhat limited, although a recent pediatric trial has demonstrated adequate pharmacokinetics, safety, and efficacy of etravirine in a small number of HIV-infected children and adolescents. In both children and adults, rash appears to be the most common adverse effect described. Despite its high genetic barrier to resistance, evidence of mutations conferring etravirine resistance has been documented in both adult and pediatric patients. Such mutations have been best described in treatment-experienced populations, including those who have never been exposed to the drug. This review describes the existing literature on the use of etravirine in the pediatric population, and highlights future and ongoing directions of investigation.

Keywords: etravirine, pediatric, human immunodeficiency virus, antiretrovirals, non-nucleoside reverse transcriptase inhibitor

\section{Introduction}

As of December 2012, an estimated 34 million people were living with human immunodeficiency virus (HIV) infection, 3.4 million of whom were children. ${ }^{1}$ In 2010, an estimated 1.8 million people died from acquired immune deficiency syndrome (AIDS), of whom 260,000 were children under the age of 15 years. ${ }^{1}$ Pediatric HIV infection follows an epidemiologic pattern distinct from infection in adults. The majority of HIV-infected young children acquire infection through the perinatal route (antepartum, intrapartum, and postpartum), with the majority becoming infected near the end of pregnancy or postpartum. Postpartum infection of infants occurs primarily through breastfeeding, which globally accounts for roughly one third of all cases of perinatal $\mathrm{HIV}^{2-4}$ The presentation of perinatal HIV infection follows a bimodal distribution, with a peak at a median of 4 months of age and another at 6 years of age. ${ }^{5}$ Progression 
of infection is much more rapid in children than in adults, with infected infants demonstrating a more profound and persistent viremia, and viral loads 1-2 logs greater during seroconversion and the early period of clinical latency. ${ }^{6,7}$ Perinatally infected children may also demonstrate a more ineffectual and impaired immunologic response to HIV infection than adults. ${ }^{6-9}$ Deleterious effects on the developing immune system may be partly to blame for this phenomenon, with thymocyte depletion, thymic atrophy, poor CD8+ T-cell response to HIV antigens, and rapid depletion of CD4+ cells potentially to blame..$^{6-9}$ Despite the predisposition of perinatally infected children to severe and rapidly progressive infection, the use of highly active antiretroviral therapy or combination antiretroviral therapy (ART) has significantly improved outcomes in HIV-infected children in both industrialized countries and in resource-limited settings. ${ }^{10-13}$ The ability to control viral replication with multiple drugs with differing mechanisms of action helps prevent the development of antiretroviral resistance and restore immunologic function. ART should be started as early as possible in perinatally infected infants. Data from the Children with HIV Early Antiretroviral Therapy (CHER) trial in South Africa demonstrated significant reductions in mortality and morbidity in perinatally infected infants who received early ART (at 6-12 weeks of age) when compared with perinatally infected infants in whom ART was deferred until specific immunologic or clinical criteria were met. ${ }^{14}$ Continuing reductions in mortality have also been documented over time in HIV-infected children as newer antiretroviral agents and approaches to management have been introduced over the last few decades. Data compiled from 1,142 perinatally infected children in Italy demonstrated reductions in mortality of $23 \%, 30 \%$, and $71 \%$ for monotherapy, double combination, and triple combination ART, respectively, compared with no therapy after a median follow-up of 3.1 years. The reduction in mortality correlated with the evolving approach to HIV treatment in children born between 1980 and $1997 .{ }^{11}$ Rates of opportunistic infections in HIV-infected children have likewise decreased significantly after the introduction of combination ART, with 5-10-fold reductions documented for many opportunistic infections in children enrolled in the Pediatric AIDS Clinical Trial 219C in the US. ${ }^{15}$ For the treatment of HIV-infected, antiretroviral-naïve children, the US National Institutes of Health currently recommends the use of combination therapy comprising a dual nucleoside/nucleotide reverse transcriptase inhibitor backbone with either a non-nucleoside reverse transcriptase inhibitor (NNRTI) or a protease inhibitor. ${ }^{16}$ Etravirine is an NNRTI of HIV type 1, first licensed for the treatment of HIV-1-infected, treatmentexperienced adults with virologic failure and evidence of NNRTI resistance in January 2007. ${ }^{17,18}$ The NNRTI class of antiretrovirals is prone to the development of broad resistance across the entire drug class, often after a single amino acid substitution resulting from mutations in the reverse transcriptase gene. ${ }^{19}$ Etravirine has demonstrated good activity against NNRTI-resistant strains of HIV both in vitro and clinically, and has a higher genetic barrier to the development of resistance than either nevirapine or efavirenz. ${ }^{20,21}$ As such, it represents a potentially useful tool in managing HIV-infected patients with multiclass-resistant HIV. Data from a large, randomized controlled trial have demonstrated the clinical safety and efficacy of etravirine when compared with placebo in adult patients on combination ART. ${ }^{21-24}$

Children infected with HIV often present unique difficulties in management not present in adult HIV-infected patients. A lack of adequate pediatric liquid or granular formulations may limit the number of available antiretroviral agents. Given the difficulties in studying new medications in children, data on newer antiretroviral agents are often lacking. Children pass through various developmental stages (including adolescence), which may lead to difficulties with treatment compliance. ${ }^{25}$ Higher weight-based dosing of antiretrovirals may be required given differences in body composition, drug absorption, and metabolism, all of which change as children grow. ${ }^{26,27}$ Further, data on the management of antiretroviralexperienced children carrying multiclass resistance are extremely limited. NNRTI therapy has been shown to be efficacious and well tolerated in HIV-infected children, although still prone to the same potential for cross-resistance across this class of antiretroviral as in adults. ${ }^{28}$ To help address this concern, etravirine was approved by the US Food and Drug Administration for use in children over the age of 6 years and over $16 \mathrm{~kg}$ of weight in March 2012. ${ }^{29}$ This coincided with the approval of a new scored $25 \mathrm{mg}$ tablet for use in children. Even though a liquid formulation is not currently available, etravirine tablets may be dissolved in water if a child is unable to swallow tablets. ${ }^{29,30}$ This review discusses the use of etravirine in pregnant women, adolescents, and children, and highlights future avenues of research.

\section{Adult experience}

The DUET (Demonstrate Undetectable viral load in patients Experienced with antiretroviral Therapy) 1 and DUET 2 trials are identically designed multinational studies which provided the first large-scale data suggesting that etravirine is efficacious in the treatment of HIV-1 infection in adults. ${ }^{21-31}$ 
Combined, both trials enrolled 1,203 HIV-infected adults and demonstrated the efficacy of etravirine compared with placebo when incorporated into an existing combination antiretroviral regimen. Subjects in the DUET 1 study were significantly more likely to demonstrate improvements in both viral load and CD4 counts after 24 weeks of therapy compared with placebo, while subjects in the DUET 2 study only demonstrated significant improvements in viral load after 24 weeks of therapy. Follow-up of the DUET cohorts at 48 weeks revealed ongoing significant improvements in viral load in the etravirine group when compared with placebo. ${ }^{23}$ Etravirine recipients also demonstrated significantly larger improvements in CD4 count than those receiving placebo. Ninety-two percent of those patients who developed an undetectable viral load after 24 weeks of etravirine sustained this level of viral suppression 48 weeks into therapy. Patients receiving etravirine were also significantly less likely to experience death or an AIDS-defining illness at this time point. Subjects from both studies continued to demonstrate significant improvement in both viral load and CD4 count at 96 weeks of follow-up. ${ }^{24}$ Of note, etravirine was well tolerated, with few adverse effects described. However, rash was noted to be twice as common in patients receiving etravirine (19\% versus $11 \%$, significantly more often than the control group) in all three follow-up studies (24 weeks, 48 weeks, and 96 weeks). ${ }^{21,23,24}$

\section{Etravirine in pregnancy}

The pharmacokinetics of etravirine in pregnancy and its effects on the fetus are not extensively studied, although the pharmacokinetics of earlier-generation NNRTI agents in pregnancy have been described. ${ }^{32-35}$ Nevirapine attains nearly equivalent concentrations in maternal and umbilical cord blood, and concentrations in amniotic fluid are roughly $75.0 \%$ of those in maternal blood. ${ }^{36,37}$ Limited data exist on efavirenz. Placental transfer of etravirine has been documented in rats, and animal studies have not demonstrated any harmful teratogenic effects. ${ }^{36}$ Furco et al described a 38-yearold woman with multidrug-resistant HIV and pregnant with a twin gestation who received etravirine $200 \mathrm{mg}$ twice daily beginning at 25 weeks' gestation in combination with darunavir, ritonavir, and enfuviritide. ${ }^{38}$ Her HIV RNA viral load improved from 4,660 copies/mL to $<50$ copies/mL, while her CD4 count decreased from 471 cells $/ \mu \mathrm{L}$ to 356 cells $/ \mu \mathrm{L}$. Etravirine trough levels were $896 \mathrm{ng} / \mathrm{mL}$ (etravirine trough values in adults have been reported to range from $192 \mathrm{ng} / \mathrm{mL}$ to $297 \mathrm{ng} / \mathrm{mL}$ ) with a peak level of $1,210 \mathrm{ng} / \mathrm{mL} 6$ hours after the dose. ${ }^{18,39}$ Levels of etravirine in cord blood at the time of delivery were $414 \mathrm{ng} / \mathrm{mL}$ in twin 1 and $345 \mathrm{ng} / \mathrm{mL}$ in twin 2 . Paired maternal-cord blood specimens were not collected, but placental transfer was estimated to have ranged from $29.0 \%$ to $46.0 \%{ }^{36,38}$ The infants were born via cesarean section at 34 weeks' gestation, and received 2 days of enfuviritide, one week of nevirapine, and 2 weeks of didanosine. ${ }^{38}$ At 4 months of age, neither infant was infected with HIV. The pharmacokinetics of etravirine were also retrospectively described in four pregnant women receiving the drug via a compassionate use exemption during the clinical development stage. ${ }^{31}$ Etravirine pharmacokinetics were found to be similar to those in nonpregnant adults. One patient demonstrated a documented cord blood/maternal blood ratio of $112 / 330 \mathrm{ng} / \mathrm{mL}$ (33.9\%). No maternal or fetal toxicity was reported. Jaworsky et al described the use of etravirine in two HIV-infected pregnant women with multiclass genotypic resistance. ${ }^{40}$ Both women received combination antiretroviral therapy with etravirine (200 mg twice daily), lamivudine, zidovudine, abacavir, tenofovir, darunavir, raltegravir, and ritonavir for one patient and etravirine (200 mg twice daily), lamivudine, zidovudine, abacavir, tenofovir, darunavir, and ritonavir for the other. One infant developed anemia and lactic acidosis over the first 2 months of life which selfresolved. Neither infant had evidence of HIV infection by 2 months of life.

\section{Pharmacokinetics of etravirine in children}

Etravirine is primarily metabolized by the hepatic cytochrome P450 (CYP) enzymes, ie, CYP3A4, CYP2C9, and CYP2C19, followed by glucuronidation. Etravirine is an inducer of CYP3A4 and an inhibitor of CYP2C9, CYP2C19, and P-glycoprotein; therefore, coadministration of drugs that are substrates of CYP3A4, CYP2C9, and CYP2C19 or are transported by P-glycoprotein may alter the therapeutic effect or adverse reaction profile of etravirine and/or the coadministered drug. ${ }^{17,18}$ Pharmacokinetic drug interactions between etravirine and protease inhibitors, azole antifungals, clarithromycin, rifamycins, and other drugs commonly coadministered in HIVinfected patients have been described elsewhere. ${ }^{41-43}$

Appropriate dosing of all antiretrovirals is of paramount importance given the prolonged duration of therapy required and the risk of selecting for resistant virus through continued exposure of replicating virus to suboptimal levels of antiretroviral agents. Unfortunately, pediatric pharmacokinetic data are sparse for newer antiretroviral agents such as etravirine (Table 1). A recent, nonrandomized, multisite, open-label Phase I study examined the pharmacokinetics of etravirine in 
Table I Comparative pharmacokinetics of etravirine in children and adults

\begin{tabular}{|c|c|c|c|c|c|c|c|}
\hline Study & Subjects & \# Subjects & $\begin{array}{l}\text { ETV dose } \\
\text { (bid) }\end{array}$ & $\begin{array}{l}\text { Mean AUC }_{12 \mathrm{~h}} \\
\mathrm{ng} \mathrm{h} / \mathrm{mL} \text { (SD) }\end{array}$ & $\begin{array}{l}\text { Mean } C_{\max } \\
\mathrm{ng} / \mathrm{mL} \text { (SD) }\end{array}$ & $\begin{array}{l}\text { Mean } C_{\text {min }} \\
\mathrm{ng} / \mathrm{mL} \text { (SD) }\end{array}$ & $\begin{array}{l}\mathrm{T}_{\max } \\
\text { hours (range) }\end{array}$ \\
\hline Kakuda et $a^{67}$ & Adults & 577 & $200 \mathrm{mg}$ & $550 I(4544)$ & ND & $393(378)$ & ND \\
\hline \multirow[t]{2}{*}{ Königs et $\mathrm{al}^{27}$} & Children $^{\mathrm{a}}$ & 41 & 4 mg/kg & $4050(3602)$ & $495(453)$ & $184(151)$ & $4(2-8)$ \\
\hline & & & $5.2 \mathrm{mg} / \mathrm{kg}$ & $6|4|(5586)$ & 757 (680) & $294(278)$ & $4(2-6)$ \\
\hline \multirow[t]{2}{*}{ Kakuda et al ${ }^{44}$} & Children $^{\mathrm{b}}$ & 41 & $5.2 \mathrm{mg} / \mathrm{kg}$ & 5764 (4044) & ND & ND & ND \\
\hline & Adolescents $^{c}$ & 60 & $5.2 \mathrm{mg} / \mathrm{kg}^{\mathrm{d}}$ & 4874 (4487) & ND & ND & ND \\
\hline
\end{tabular}

Notes: ${ }^{a}$ Children 6-17 years of age; b children 6-12 years of age; children 12-18 years of age; ${ }^{\mathrm{d}} 200 \mathrm{mg}$ maximum dose.

Abbreviations: ETV, etravirine; $\mathrm{AUC}_{12 \mathrm{~h}}$, area under the plasma concentration-time curve from time of administration to 12 hours after dosing; SD, standard deviation; $\mathrm{C}_{\max }$, maximum plasma concentration; $\mathrm{C}_{\min }$, minimum plasma concentration; $\mathrm{T}_{\max }$, time to reach the maximum plasma concentration; $\mathrm{ND}$, not done.

treatment-experienced children and adolescents. ${ }^{27}$ Forty-two patients aged 6-17 years on combination antiretroviral therapy with an undetectable viral load were assessed. Etravirine was added to an existing antiretroviral regimen at a dose of $4 \mathrm{mg} / \mathrm{kg}$ twice daily in the first stage of the trial, followed by $5.2 \mathrm{mg} / \mathrm{kg}$ twice daily in the second stage. The maximum plasma concentration, minimum plasma concentration, and area under the plasma concentration-time curve from time of administration to 12 hours after dosing $\left(\mathrm{AUC}_{12 \mathrm{~h}}, \mathrm{ng} * \mathrm{~h} / \mathrm{mL}\right)$ were all similar to adult reference data at the $4 \mathrm{mg} / \mathrm{kg}$ dose. However, at the $5.2 \mathrm{mg} / \mathrm{kg}$ dose, these same values were $67.8 \%, 58.9 \%$, and $65.4 \%$ higher than adult reference values. ${ }^{27}$ Children tended toward higher exposure than adolescents, although tremendous variability in levels was noted, likely due to a single outlier in the study. Interindividual variability was high in the study, as is often seen in pediatric patients, although $90 \%$ confidence intervals for pharmacokinetic parameters remained in an 80\%-125\% range for referenced adult values. ${ }^{26}$ No serious adverse events were reported during the study and no detectable viral loads were documented. Kakuda et al presented pharmacokinetic data from the 101 pediatric participants in the PIANO (Pediatric Trial with Intelence as an Active NNRTI Option) study at the Sixth International AIDS Society conference in $2011 .{ }^{44}$ A total of 476 etravirine plasma concentration samples were available from these participants 24 weeks into the study. The mean $\mathrm{AUC}_{12 \mathrm{~h}}$ in children aged 6 to $<12$ years was similar to the mean $\mathrm{AUC}_{12 \mathrm{~h}}$ obtained in adults in the DUET studies (Table 1). Adolescents were reported to possess slightly lower mean $\mathrm{AUC}_{12 \mathrm{~h}}$ levels than adults in the DUET study $(4,874 \mathrm{ng} * \mathrm{~h} / \mathrm{mL}$ versus 5,501 $\mathrm{ng} * \mathrm{~h} / \mathrm{mL})$. A negative correlation was seen between $\mathrm{AUC}_{12 \mathrm{~h}}$ and weight.

One common problem in treating HIV-infected children is a lack of adequate pediatric formulations, such as liquids or granules, for many antiretrovirals, particularly newer compounds. Schöller-Gyüre et al assessed the bioavailability of a $100 \mathrm{mg}$ etravirine tablet dispersed in water and the $25 \mathrm{mg}$ pediatric tablet (taken as four tablets) in comparison with a $100 \mathrm{mg}$ adult tablet. ${ }^{30}$ Thirty-seven HIV-negative volunteers were assessed in a randomized, three-period, crossover trial with 14-day washout periods. No significant differences between any of the formulations were noted in the maximum plasma concentration of etravirine or the AUC for the period extending from the last dose of etravirine until an absence of detectable etravirine levels, suggesting comparable pharmacokinetic exposure when etravirine tablets are dissolved in water. $^{30}$

\section{Safety and efficacy of etravirine in children}

The initial descriptions of etravirine use in children were primarily anecdotal. Palladino et al reported on two HIVinfected, antiretroviral-experienced children aged 6 and 10 years with virologic failure receiving etravirine in combination with enfuvirtide as part of new antiretroviral regimens. ${ }^{45}$ Both patients harbored multiple genotypic mutations to the nucleoside/nucleotide reverse transcriptase inhibitor, NNRTI, and protease inhibitor classes of antiretrovirals. The 6-year-old patient demonstrated a 2.5 fold improvement in HIV viral load (4.9 $\log _{10}$ copies/mL to $2.0 \log _{10}$ copies $/ \mathrm{mL}$ ) and minimal change in CD4 count. The 10-year-old patient demonstrated a 2.6-fold improvement in viral load (4.5 $\log _{10}$ copies/mL to $1.7 \log _{10}$ copies $/ \mathrm{mL}$ ) and an improvement in his CD4 count from 221 cells/ $\mu \mathrm{L}$ to 571 cells $/ \mu \mathrm{L}$. No data on adverse effects potentially attributable to etravirine were reported. ${ }^{45}$ Rosso et al detailed the use of etravirine in an antiretroviral-experienced 15-year-old boy with genotypic evidence of NNRTI resistance and failure of a nevirapine-based antiretroviral regimen. ${ }^{46}$ After one month of therapy with abacavir, lamivudine, darunavir, ritonavir, and etravirine, he developed an undetectable viral load for the first time in his life, and his viral load remained undetectable through the first year of follow-up. His CD4 count improved from 287 cells $/ \mu \mathrm{L}$ to 706 cells $/ \mu \mathrm{L}$ (16\% to $18 \%$, respectively). ${ }^{46}$ The youngest patient to receive etravirine was described by Vigano et al who reported the use of etravirine 
rescue therapy in combination with darunavir and ritonavir in a 24-month-old boy with multiclass-resistant HIV infection failing multiple antiretroviral regimens. ${ }^{47}$ The etravirine was dosed at $50 \mathrm{mg}$ twice daily initially, and increased to $100 \mathrm{mg}$ twice daily 2 months into therapy. Etravirine trough values were $650 \mathrm{ng} / \mathrm{mL}$, somewhat higher than trough levels reported in adults. ${ }^{18,39}$ The regimen was well tolerated and the child developed an undetectable viral load which was maintained during the follow-up period of 15 months, concurrent with a CD4 increase from 14 cells $/ \mu \mathrm{L}$ to 1,294 cells $/ \mu \mathrm{L}$ and a CD4 percentage increase from $1.9 \%$ to $26.9 \%$.

Several recently published larger studies have shed new light on the potential efficacy of etravirine in HIV-infected children. Briz et al retrospectively described the use of etravirine in $23 \mathrm{HIV}$-infected pediatric patients in a multicenter study. ${ }^{48}$ Five antiretroviral-experienced children aged 5-12 years and 18 adolescents aged 13-18 years, all but one of whom had evidence of genotypic NNRTI resistance and had failed therapy with either efavirenz or nevirapine, were retrospectively assessed after etravirine was added to their failing antiretroviral regimen. Children received etravirine at $5.2 \mathrm{mg} / \mathrm{kg}$ twice daily and adolescents at $200 \mathrm{mg}$ twice daily. Pre-etravirine median plasma HIV-1 RNA levels were 29,000 copies/mL $\left(4.5 \log _{10}\right)$ with a median CD4 count of 445 cells $/ \mu \mathrm{L}$ and a CD $4 \%$ of $19.6 \%$. Following the use of etravirine for a median duration of 48 weeks, $87 \%$ of patients achieved a viral load of $<400$ copies $/ \mathrm{mL}$, and CD4 counts improved to a median value of 571 cells $/ \mu \mathrm{L}$. All four children who failed to respond to etravirine-based therapy were found to harbor mutations associated with etravirine resistance (E138A, Y181I, G190A, and K101E with G190A/S). ${ }^{48}$ Etravirine was well tolerated with no significant adverse reactions reported. Five of the 18 adolescents (27.8\%) developed a rash, although this did not lead to discontinuation of the drug. Roughly two thirds of the patients reported good or complete adherence to their etravirine-based regimens. ${ }^{48}$
PIANO represents the only prospective study of etravirine in children (Table 2). ${ }^{49}$ This multisite, multinational Phase II study composed of 101 children and adolescents was in part the basis upon which the US Food and Drug Administration approved this drug for use in children over the age of 6 years. Treatment-experienced, HIV-1-infected children aged $6-12$ years and adolescents aged 12 to $<18$ years with virologic failure (mean viral load at enrollment of $3.9 \log _{10}$ in children and $4.0 \log _{10}$ in adolescents) and no evidence of genotypic resistance to etravirine were enrolled. Participants received etravirine at a dose of $5.2 \mathrm{mg} / \mathrm{kg}$ twice daily (maximum dose $200 \mathrm{mg}$ ), in addition to a background antiretroviral regimen of the investigator's choosing. Results were initially reported after 24 weeks of therapy. As in adults, rash was the most common adverse effect, leading to etravirine discontinuation in four patients (4.0\%). Twenty-one percent of patients experienced at least one grade 2 adverse event felt to be at least possibly attributable to etravirine. Sixty-five percent of patients achieved a viral load $<400$ copies/mL ( $63 \%$ of adolescents and $68 \%$ of children), while improvements in CD4 cell count were noted in both groups, with a mean increase of 125 cells $/ \mu \mathrm{L}$ in children and 104 cells $/ \mu \mathrm{L}$ in adolescents. Of note, adolescents were less likely to develop a viral load $<50$ copies $/ \mathrm{mL}$ than children $(48.0 \%$ versus $59.0 \%) .{ }^{49}$ The increases in CD4 cell count were higher than that noted in adult patients at 24 weeks in the previously discussed DUET trials (mean, 86 cells $/ \mu \mathrm{L}$ ). Virologic failure was documented in 43 of the 101 subjects, 33 of whom were classified as nonresponders and 10 who demonstrated virologic failure after an initial improvement in viral load. Twenty-eight of these 43 subjects had genotypic resistance testing results available at the time of virologic failure. Fifty-four percent demonstrated mutations associated with etravirine resistance, of which Y181C, E138A, and V90I were most predominant. ${ }^{49}$ Adolescents were more likely to have etravirine-associated resistance mutations $(60.0 \%$ versus $37.5 \%)$ than children.

Table 2 Outcome comparisons between the DUET I, DUET 2, and PIANO trials

\begin{tabular}{|c|c|c|c|c|}
\hline Study & Population & Subjects (n) & $\% \mathbf{V L}<\mathbf{5 0}$ (copies/mL) & $\begin{array}{l}\text { Mean change CD4 } \\
\text { count (cells/ } \mu \mathrm{L})\end{array}$ \\
\hline \multirow[t]{2}{*}{ DUET I (24 weeks) ${ }^{21}$} & Adults & 612 & $\mathrm{ETV} \rightarrow 56 \%$ & $\mathrm{ETV} \rightarrow+89$ cells $/ \mu \mathrm{L}$ \\
\hline & & & Placebo $\rightarrow 39 \%$ & Placebo $\rightarrow+64$ cells $/ \mu \mathrm{L}$ \\
\hline \multirow[t]{2}{*}{ DUET 2 (24 weeks) ${ }^{22}$} & Adults & 591 & ETV $\rightarrow 62 \%$ & $\mathrm{ETV} \rightarrow+78$ cells $/ \mu \mathrm{L}$ \\
\hline & & & Placebo $\rightarrow 44 \%$ & Placebo $\rightarrow+66$ cells $/ \mu \mathrm{L}$ \\
\hline \multirow[t]{2}{*}{ PIANO (24 weeks) ${ }^{49}$} & Children & $4 I$ & $59 \%$ & +125 cells $/ \mu \mathrm{L}$ \\
\hline & Adolescents & 60 & $48 \%$ & +104 cells $/ \mu \mathrm{L}$ \\
\hline \multirow[t]{2}{*}{ PIANO (48 weeks) ${ }^{50}$} & Children & $4 I$ & $68 \%$ & +178 cells $/ \mu \mathrm{L}$ \\
\hline & Adolescents & 60 & $48 \%$ & $+|4|$ cells $/ \mu \mathrm{L}$ \\
\hline
\end{tabular}

Abbreviations: DUET, Demonstrate Undetectable viral load in patients Experienced with antiretroviral Therapy; ETV, etravirine; PIANO, Pediatric Trial with Intelence as an Active NNRTI Option; VL, viral load. 
Ninety-five percent adherence levels were also lower in adolescents as assessed by pill count $(37.0 \%$ in adolescents versus $44.0 \%$ in children). Follow-up data at 48 weeks from the PIANO trial were presented at the 2012 International AIDS Conference. ${ }^{50}$ Seventy-six of the original 101 patients completed 48 weeks of therapy. Rash was the most common adverse event felt to be at least possibly related to etravirine use, occurring in 18 of all enrolled patients over the course of the 48 weeks (18.0\%). Overall, improvements were still noted in viral load and CD4 counts at this time point. However, adolescents were again less likely to experience a viral load $<50$ copies $/ \mathrm{mL}$ (48.0\% versus $68.0 \%)$ and also demonstrated smaller improvements in CD4 count (141 cells/ $\mu \mathrm{L}$ versus 178 cells/ $\mu \mathrm{L}$ ) when compared with children. $95 \%$ adherence levels were lower in adolescents compared with children at 48 weeks $(35.0 \%$ versus $46.0 \%$ by pill count, respectively). Eighteen of $30(60 \%)$ patients experiencing virologic failure undergoing genotypic resistance testing had mutations associated with etravirine resistance. Commonly encountered mutations associated with etravirine resistance included the Y181C $(\mathrm{n}=8)$, E138A $(\mathrm{n}=3), \operatorname{L100I}(\mathrm{n}=3)$, and V90I $(n=3)$ mutations. The differences between adolescents and children seen in both the 24-week and 48-week follow-up data may in part be explained by differences in adherence, disease severity, less prior NNRTI use by children $(63.4 \%$ versus $70.0 \%$ ), and weight-based dosing utilized in children but not adolescents..$^{50,51}$

\section{Development of etravirine resistance in children}

One of the advantages of etravirine is its ability to retain activity against strains of HIV resistant to the earliergeneration NNRTI agents, efavirenz and nevirapine. ${ }^{20,21}$ However, the potential for etravirine resistance still exists (Table 3). In 2007, 13 etravirine resistance-associated mutations conferring at least a $25 \%$ reduction in response to etravirine were identified from 24-week analyses of pooled data from the DUET 1 and DUET 2 trials. ${ }^{52}$ This work was later expanded, and a weighted genotypic resistance score was subsequently proposed based upon assigning a relative score to each of 17 etravirine resistance-associated mutations based on their effect on virologic response. ${ }^{53}$ Categorization of scores between $0-2,2.5-3.5$, and $\geq 4$ were associated with the highest, intermediate, and reduced responses to etravirine, respectively. The level of resistance was associated with the number of resistance-associated mutations, with multiple mutations typically required to lead to an impaired virologic response. Aulicino et al reported on a group of $71 \mathrm{HIV}$-infected
Table 3 Frequency of etravirine resistance-associated mutations in children

\begin{tabular}{llll}
\hline Study & No genotypes & ETV RAM & $\begin{array}{l}\text { Mutation } \\
\text { frequency (\%) }\end{array}$ \\
\hline Aulicino et al $^{54}$ & 71 & LI00I & 15.5 \\
Germanaud et al $^{56}$ & 30 & YI8IC & 16.6 \\
& & GI90A & 13.3 \\
& & KIOIE & 3.3 \\
Puthanakit et al $^{57}$ & \multirow{2}{*}{120} & YI8IC & 43.3 \\
& & GI90A & 28.3 \\
& & LI00I & 2.5 \\
& \multirow{2}{*}{45} & GI90S & 2.5 \\
Tolle et al & YI8IC & 24.4 \\
& & GI90A & 20.0 \\
& \multirow{2}{*}{84} & KIOIE & 13.3 \\
Vaz et al & & YI8IC/I & 32.1 \\
& & GI90A/S & 30.9 \\
& & KIOIE & 17.8 \\
\hline
\end{tabular}

Abbreviations: No, number; ETV, etravirine; RAM, resistance-associated mutations.

children (38 children and 33 adolescents) from Argentina undergoing genotypic resistance testing for treatment failure. ${ }^{54}$ NNRTI agents had been utilized by $46.4 \%$ of patients in the last treatment regimen prior to resistance testing. Of the 50 patients who had received any prior NNRTI therapy, $45(90 \%)$ had evidence of NNRTI resistance-associated mutations, of which 23 (51.1\%) carried the K103N mutation, a common NNRTI resistance-associated mutation conferring resistance to nevirapine and efavirenz. ${ }^{55}$ This mutation was associated with the L100I mutation $47.8 \%$ of the time. The $\mathrm{K} 103 \mathrm{~N}$ mutation had no effect on the virologic response to etravirine in the DUET studies. ${ }^{53}$ However, the L100I mutation has been identified as an etravirine resistance-associated mutation. ${ }^{53}$ When analyzing and weighing the combination of various resistance-associated mutations using the etravirine resistance score proposed by Vingerhoets et al, Aulicino et al demonstrated that $2.8 \%$ of the patients in the study had a predicted reduced response to etravirine (score $\geq 4$ ), and $19.7 \%$ had a predicted intermediate response to etravirine (score 2.5-3.5). ${ }^{54}$ Germanaud et al analyzed 37 HIV-1 infected children in Mali on NNRTI therapy (most on nevirapinebased regimen), 30 of whom underwent genotypic resistance testing for virologic failure. ${ }^{56}$ Mutations associated with etravirine resistance were detected in eight children (Y181C in five children, G190A in four children, and K101E in one child). Puthanakit et al described 120 HIV-infected children from Thailand on NNRTI-containing regimens for a median of 23.7 months undergoing genotypic resistance testing for virologic failure. ${ }^{57}$ NNRTI mutations were found in $98.3 \%$ of children. Four different NNRTI mutations associated with etravirine resistance were reported (L100I, Y181C, G190S, 
and G190A). Etravirine-weighted genotypic scores $\geq 4$ (likely to confer reduced susceptibility to etravirine) were reported in $47.5 \%$ of patients despite a lack of prior etravirine exposure. One aspect of this study discussed by the authors centered on the resource-limited setting in which it was conducted.

The lack of routine viral load monitoring and resistance testing in such settings may allow continued exposure of replicating HIV to an ineffective antiretroviral regime, thus permitting the accumulation of resistance-associated mutations. This concept was illustrated in three similar studies from Mozambique, Uganda, and Botswana. Vaz et al described 84 children undergoing genotypic resistance testing in Mozambique who had received at least 6 months of a nevirapine-based antiretroviral regimen and were in virologic failure. ${ }^{58}$ These children were analyzed for the presence of resistance mutations. Ninety-two percent of children had evidence of nevirapine resistance. Five children $(6 \%)$ harbored a combination of mutations conferring etravirine resistance. Two patients carried the K101E, Y181C, and G190A mutations, one carried the K101E, V179A, Y181C, and G190A mutations, one carried the K101E, Y181C, and G190A mutations, and one carried the K101E, Y181C, and G190A mutations. All subjects had combined mutations with an etravirine-weighted genotypic score $>4.0$ likely to confer reduced susceptibility to etravirine. A Ugandan study of 35 HIV-infected children failing combination antiretroviral therapy with an NNRTI-based regimen demonstrated $35 \%$ reduced phenotypic susceptibility to etravirine (foldchange $>2.9$ by PhenoSense GTTM, South San Francisco, CA, USA), despite no prior etravirine use. ${ }^{59}$ Tolle et al assessed 45 HIV-infected children with a mean age of 5.9 (range 1-11) years, undergoing genotypic resistance testing for virologic failure in Botswana. ${ }^{60}$ All children had received NNRTI therapy prior to genotypic resistance testing. Etravirine resistance-associated mutations were noted in 21 patients $(46.7 \%)$. The Y181C mutation was noted in $24.4 \%$ of patients, with the G190A mutation in $20.0 \%$ and the K101E mutation detected in $13.3 \%$. Of note, 20 of these 21 patients with etravirine resistance-associated mutations had been exposed to nevirapine, while just one of six patients exposed to efavirinez developed an etravirine resistance-associated mutation. This association between nevirapine resistance and predicted reduced response to etravirine has been reported previously in adults. ${ }^{61,62}$ Nevirapine was the only antiretroviral shown to be associated with an etravirine weighted genotypic score of $\geq 2.5$, predicting intermediate response to etravirine in a multivariable logistic regression model of HIV-infected adults in Thailand on
ART undergoing genotypic resistance testing for virologic failure. ${ }^{61}$ Similarly, Taiwo et al reported that roughly half of 91 HIV-infected adults failing nevirapine-based ART had a predicted suboptimal response to etravirine. ${ }^{62}$

\section{Future directions}

Additional studies of etravirine in children are in progress. NCT00980538 is a National Institutes of Health (NIH)sponsored trial in the recruitment phase which will continue to follow children and adolescents who were previously enrolled in etravirine trials. ${ }^{63}$ Among other endpoints, investigators will weight-adjust the dosage of etravirine as the trial progresses, and assess adverse effects every 3 months. P1090 is an NIH-sponsored study developed by the International Maternal Pediatric Adolescent AIDS Clinical Trials Group. ${ }^{64}$ It is a open-label Phase I/II trial to evaluate the safety, tolerability, pharmacokinetics, and antiviral activity of etravirine in antiretroviral treatmentexperienced HIV-infected infants and children aged between 2 months and 6 years. NCT00855335 is an NIH-sponsored trial in the recruitment phase assessing the pharmacokinetics of etravirine (as well as other antiretroviral agents) in HIV-1-infected pregnant women. ${ }^{65}$ NCT00977756 is also an NIH-sponsored trial in the recruitment phase assessing the pharmacokinetics and adverse effect profiles of raltegravir, maraviroc, and etravirine in children and adolescents between the ages of 6 and 21 years. ${ }^{66}$ The effect that Tanner stage and viral polymophisms may have on the pharmacokinetics of etravirine containing regimens will be assessed, as will the adverse effect profile. Given the potential for development of resistance to etravirine, and the likely role this will play in the treatment of children and adolescents with pre-existing NNRTI resistance, more study will be needed on the effect of antiretroviral compliance on the development of etravirine resistance.

\section{Conclusion}

As more data become available, it is hoped that etravirine will take a place in the armamentarium of antiretroviral drugs available to HIV-infected children. It is to be used in combination regimens in antiretroviral-experienced children with virologic failure and evidence of drug resistance. The importance of adherence and appropriate resistance testing must be taken into account, given that resistance to this agent may develop even prior to exposure. Several studies of etravirine are ongoing which aim to address shortcomings in our knowledge of this drug in the pediatric population. 


\section{Acknowledgment}

The authors wish to thank Mark Mirochnick and Tim Cressey for their critical review of the manuscript and helpful suggestions.

\section{Disclosure}

The authors report no conflicts of interest in this work.

\section{References}

1. United Nations Programme on HIV/AIDS. 2010 Global Report. Available from: http://www.unaids.org. Accessed June 27, 2013.

2. Kourtis A, Lee F, Abrams E, Jamieson D, Bulterys M. Mother-to-child transmission of HIV-1: timing and implications for prevention. Lancet Infect Dis. 2006;6:726-732.

3. Kourtis A, Jamieson D, de Vincenzi I, et al. Prevention of human immunodeficiency virus-1 transmission to the infant through breastfeeding: new developments. Am J Obstet Gynecol. 2007;197: S113-S122.

4. Soeiro R, Rubinstein A, Rashbaum W, Lyman W. Maternofetal transmission of AIDS: frequency of human immunodeficiency virus type 1 nucleic acid sequences in human fetal DNA. J Infect Dis. 1992;166: 699-703.

5. Auger I, Thomas P, De Gruttola V, et al. Incubation periods for paediatric AIDS patients. Nature. 1988;336:575-577.

6. Abrams E, Weedon J, Steketee R, et al. Association of human immunodeficiency virus (HIV) load early in life with disease progression among HIV-infected infants. J Infect Dis. 1998;178:101-108.

7. Blanche S, Newell M, Mayaux M, et al. Morbidity and mortality in European children vertically infected by HIV-1: the French pediatric HIV infection study group and European collaborative study. J AIDS. $1997 ; 14: 442-450$

8. Sandberg J, Fast N, Jordan K, et al. HIV-specific CD8+ T cell function in children with vertically acquired HIV-1 infection is critically influenced by age and the state of the CD4+ T cell compartment. J Immunol. 2003; $170: 4403-4410$

9. Ye P, Kirschner D, Kourtis A. The thymus during HIV disease: role in pathogenesis and in immune recovery. J Immunol. 2004;170:4403-4410.

10. Puthanakit T, Aurpibul L, Oberdorfer P, et al. Hospitalization and mortality among HIV-infected children after receiving highly active antiretroviral therapy. Clin Infect Dis. 2007;44:599-604.

11. de Martino M, Tovo P, Balducci M, et al. Reduction in mortality with availability of antiretroviral therapy for children with perinatal HIV-1 infection. JAMA. 2000;284:190-197.

12. Viani R, Araneta M, Deville J, Spector S. Decrease in hospitalization and mortality rates among children with perinatally acquired HIV type 1 infection receiving highly active antiretroviral therapy. Clin Infect Dis. 2004;39:725-731.

13. Resino S, Rosino R, Bellón J, et al. Clinical outcomes improve with highly active antiretroviral therapy in vertically HIV type-1-infected children. Clin Infect Dis. 2006;43:243-252.

14. Violari A, Cotton M, Gibb D, et al. Early antiretroviral therapy and mortality among HIV-infected infants. $N$ Engl J Med. 2008;359: 2233-2244.

15. Gona P, Van Dyke R, Williams $\mathrm{P}$, et al. Incidence of opportunistic and other infections in HIV-infected children in the HAART era. JAMA. 2006;296:292-300.

16. National Institutes of Health. Guidelines for the use of antiretroviral agents in Pediatric HIV infection. Available from: http://aidsinfo.nih. gov/contentfiles/Ivguidelines/pediatricguidelines.pdf. Accessed June 27, 2013.

17. U.S. Food and Drug Administration. Approval of etravirine for treatment-experienced adult patients. Available from: http://www.fda. gov/ForConsumers/ByAudience/ForPatientAdvocates/HIVandAIDSActivities/ucm124019.htm. Accessed June 27, 2013.
18. Tibotec Inc. Intelence (etravirine) tablets for oral use. Full prescribing information. Available from: http://www.intelence.com/shared/product/ intelence/prescribing-information.pdf. Accessed June 27, 2013.

19. Delaugerre C, Rohban R, Simon A, et al. Resistance profile and crossresistance of HIV-1 among patients failing a non-nucleoside reverse transcriptase inhibitor-containing regime. J Med Virol. 2001;65:445-448.

20. Vingerhoets J, Azijn H, Fransen E, et al. TMC125 displays a high genetic barrier to the development of resistance: evidence from in vitro selection experiments. J Virol. 2005;79:12773-12782.

21. Madruga J, Cahn P, Grinsztejn B, et al. Efficacy and safety of TMC125 (etravirine) in treatment-experienced HIV-1-infected patients in DUET-1: 24-week results from a randomized, double-blind, placebocontrolled trial. Lancet. 2007;370:29-38.

22. Lazzarin A, Campbell T, Clotet B, et al. Efficacy and safety of TMC 125 (etravirine) in treatment-experienced HIV-1-infected patients in DUET-2: 24-week results from a randomized, double-blind, placebocontrolled trial. Lancet. 2007;370:39-48.

23. Katlama C, Haubrich R, Lalezari J, et al. Efficacy and safety of etravirine in treatment-experienced, HIV-1 patients: pooled 48-week analysis of two randomized, controlled trials. AIDS. 2009;23:2289-2300.

24. Katlama C, Clotet B, Mills A, et al. Efficacy and safety of etravirine at week 96 in treatment-experienced HIV type-1-infected patients in the DUET-1 and DUET-2 trials. Antivir Ther. 2010;15:1045-1052.

25. Chandwani S, Koenig L, Sill A, et al. Predictors of antiretroviral medication adherence among a diverse cohort of adolescents with HIV. J Adolesc Health. 2012;51:242-251.

26. Menson E, Walker A, Sharland M, et al. Underdosing of antiretrovirals in UK and Irish children with HIV as an example of problems in prescribing medicines to children, 1997-2005: cohort study. BMJ. 2006;332:1183-1187.

27. Königs C, Feiterna-Sperling C, Esposito S, et al. Pharmacokinetics and short-term safety and tolerability of etravirine in treatment-experienced HIV-1-infected children and adolescents. AIDS. 2012;26:447-455.

28. Starr S, Fletcher C, Spector S, et al. Efavirenz liquid formulation in human immunodeficiency virus-infected children. Pediatr Infect Dis J. 2002;21:659-663.

29. U.S. Food and Drug Administration. Intelence (etravirine): pediatric dosing recommendations and new scored $25 \mathrm{mg}$ tablet for pediatric dosing. U.S. Food and Drug Administration. Available from: http:// www.fda.gov/ForConsumers/ByAudience/ForPatientAdvocates/ HIVandAIDSActivities/ucm297471.htm. Accessed June 29, 2013.

30. Schöller-Gyüre M, Kakuda T, van Sollingen-Ristea R. Bioavailability of the $100 \mathrm{mg}$ etravirine tablet dispersed in water and of the $25 \mathrm{mg}$ pediatric tablet formulation. Abstract MOPE0184 presented at the XVIIth International AIDS Conference, August 3-8, 2008, Mexico City, Mexico.

31. Izurieta P, Kakuda T, Feys C, Witek J. Safety and pharmacokinetics of etravirine in pregnant HIV-1-infected women. HIV Med. 2011;12: 257-258.

32. Cressey TR, Stek A, Capparelli E, et al. Efavirenz pharmacokinetics during the third trimester of pregnancy and postpartum. $J$ Acquir Immune Defic Syndr. 2012;59:245-253.

33. Capparelli EV, Aweeka F, Hitti J, et al. Chronic administration of nevirapine during pregnancy: impact of pregnancy on pharmacokinetics. HIV Med. 2008;9:214-220.

34. Benaboud, Ekouévi DK, Urien S, et al. Population pharmacokinetics of nevirapine in HIV-1-infected pregnant women and their neonates. Antimicrob Agents Chemother. 2011;55:331-339.

35. Lamorde M, Byakika-Kibwika P, Okaba-Kayom V, et al. Suboptimal nevirapine steady-state pharmacokinetics during intrapartum compared with postpartum in HIV-1-seropositive Ugandan women. $J$ Acquir Immune Defic Syndr. 2010;55:345-350.

36. Else L, Taylor S, Back D, Khoo S. Pharmacokinetics of antiretroviral drugs in anatomical sanctuary sites: the fetal compartment (placenta and amniotic fluid). Antivir Ther. 2011;16:1139-1147.

37. Gingelmaier A, Kurowski M, Kästner R, et al. Placental transfer and pharmacokinetics of lopinavir and other protease inhibitors in combination with nevirapine at delivery. AIDS. 2006;20:1737-1743. 
38. Furco A, Gosrani B, Nicholas S, et al. Successful use of darunavir, etravirine, enfuviritide and tenofovir/emtricitabine in pregnant woman with multiclass HIV resistance. AIDS. 2009;23:434-435.

39. Gutiérrez-Valencia A, Martin-Peña R, Torres-Comejo A, et al. Intracellular and plasma pharmacokinetics of $400 \mathrm{mg}$ etravirine once daily versus $200 \mathrm{mg}$ of etravirine twice daily in HIV-infected patients. J Antimicrob Chemother. 2012;67:681-684.

40. Jaworsky D, Thompson C, Yudin M, et al. Use of newer antiretroviral agents, darunavir and etravirine with or without raltegravir, in pregnancy: a report of two cases. Antivir Ther. 2010;15:677-680.

41. Schöller-Gyüre M, Kakuda TN, Raoof A, De Smedt G, Hoetelmans RMW. Clinical pharmacokinetics and pharmacodynamics of etravirine. Clin Pharmacokinet. 2009;48:561-574.

42. Kakuda TN, Schöller-Gyüre M, Hoetelmans RMW. Clinical perspective on antiretroviral drug-drug interactions with the non-nucleoside reverse transcriptase inhibitor etravirine. Antivir Ther. 2010;15:817-829.

43. Kakuda TN, Schöller-Gyüre M, Hoetelmans RMW. Pharmacokinetic interactions between etravirine and non-antiretroviral drugs. Clin Pharmacokinet. 2011;50:25-39.

44. Kakuda T, Green B, Morrish G, et al. Population pharmacokinetics of etravirine in HIV-1 infected, treatment-experienced children and adolescents ( 6 to $<18$ years). Abstract TULBPE025 presented at the 6th International AIDS Society Conference on HIV Pathogenesis, Treatment and Prevention, July 17-20, 2011, Rome, Italy.

45. Palladino C, Briz V, González-Tomé MI, et al. Short communication: evaluation of the effect of enfuviritide in $11 \mathrm{HIV}-1$ vertically infected pediatric patients outside clinical trials. AIDS Res Hum Retroviruses. 2010;26:301-305.

46. Rosso R, Bernardini C, Bruzzone B, et al. Efficacy and safety of darunavir and etravirine in an antiretroviral multi-experienced youth with vertically HIV-1 infection. Eur J Med Res. 2009;14:136-138.

47. Vigano A, Meroni L, Marchetti G, et al. Successful rescue therapy with a darunavir/ritonavir and etravirine antiretroviral regimen in a child with vertically acquired multi-drug resistant HIV-1. Antivir Ther. 2008;13: 839-843.

48. Briz V, Palladino C, Navarro M, et al. Etravirine-based highly active antiretroviral therapy in HIV-1 infected paediatric patients. HIV Med. 2011;12:442-446.

49. Tudor-Williams G, Cahn P, Chokephaibulkit K, et al. Safety and efficacy of etravirine in HIV-1 infected, treatment experienced children and adolescents ( 6 to $<18$ years): week 24 primary analysis of the phase II PIANO study. Abstract TULBPE027 presented at the 6th International AIDS Society Conference on HIV Pathogenesis, Treatment and Prevention, July 17-20, 2011, Rome, Italy.

50. Tudor-Williams G, Cahn P, Chokephaibulkit K, et al. Safety and efficacy of etravirine in HIV-1 infected, treatment-experienced children and adolescents: PIANO 48-week results. Abstract TUAB0204 presented at the XIX International AIDS Conference, July 22-27, 2012, Washington, DC.

51. Penazzato M, Giaquinto C. Role of non-nucleoside reverse transcriptase inhibitors in treating HIV-infected children. Drugs. 2011;71: 2131-2149.

52. Vingerhoets J, Buelens A, Peeters M, et al. Impact of baseline NNRTI mutations on the virological response to TMC125 in the phase III clinical trials DUET-1 and DUET-2. Antivir Ther. 2007;12 Suppl 1:S34.

53. Vingerhoets J, Tambuyzer L, Azijn H, et al. Resistance profile of etravirine: combined analysis of baseline genotypic and phenotypic data from the randomized, controlled phase III clinical studies. AIDS. 2010;24:503-514.
54. Aulicino P, Rocco C, Mecikovsky D, et al. HIV type-1 genotypic resistance profiles in vertically infected patients from Argentina reveals an association between K103 N+L100I and L74V mutations. Antivir Ther. 2010;15:641-650.

55. Bannister W, Ruiz L, Cozzi-Lepri A, et al. Comparison of genotypic resistance profiles and virological responses between patients starting nevirapine and efavirenz in EuroSIDA. AIDS. 2008;22:367-376.

56. Germanaud D, Derache A, Traore M, et al. Level of viral load and antiretroviral resistance after 6 months of non-nucleoside reverse transcriptase inhibitor first-line treatment in HIV-1-infected children in Mali. J Antimicrob Chemother. 2010;65:118-124.

57. Puthanakit T, Jourdain G, Hongsiriwon S, et al. HIV-1 drug resistance mutations in children after failure of first-line non-nucleoside reverse transcriptase inhibitor-based antiretroviral therapy. HIV Med. 2010;11: 565-572.

58. Vaz P, Chaix M, Jani I, et al. Risk of extended viral resistance in human immunodeficiency virus-1 infected Mozambican children after first-line treatment failure. Pediatr Infect Dis J. 2009;28:e283-e287.

59. Kekitinwa A, Friedman D, Coakley E, Lie Y, Granziano F. Profiling etravirine resistance in Ugandan children with extended failure of a NNRTI-inclusive regimen as first-line ART. Abstract 891 presented at the 16th Conference on Retroviruses and Opportunistic Infections, February 8-11, 2009, Montréal, Canada.

60. Tolle M, Howard L, Kirk B, Gomila A, Schwarzwald H, Anabwani G. Reverse transcriptase genotypes in Pediatric patients failing initial antiretroviral therapy in Gaborone, Botswana. J Int Assoc Physicians AIDS Care (Chic). 2012;11:260-268.

61. Kiertiburanakul S, Wiboonchutikul S, Sukasem C, Chantratita W, Sungkanuparph S. Using of nevirapine is associated with intermediate and reduced response to etravirine among HIV-infected patients who experienced virologic failure in a resource-limited setting. J Clin Virol. 2010;47:330-334

62. Taiwo B, Chaplin B, Penugonda S, et al. Suboptimal etravirine activity is common during failure of nevirapine-based combination antiretroviral therapy in a cohort infected with non-B subtype HIV-1. Curr HIV Res. 2010;8:194-198.

63. Clinical Trials.gov. TMC125-TiDP35-C239-Continued access to etravirine (ETR) in treatment experienced HIV-1 infected children and adolescents. Available from: http/www.clinicaltrials.gov. Accessed June 27, 2013.

64. Clinical Trials.gov. Evaluating the safety and tolerability of etravirine in HIV-1 infected infants and children. Available from: http://clinicaltrials. gov/show/NCT01504841. Accessed June 26, 2013.

65. Clinical Trials.gov. A study to assess the pharmacokinetics (blood levels) of TMC14 (darunavir) taken with ritonavir and/or TMC125 (etravirine) and TMC278 (rilpivirine) in HIV-1 infected pregnant women. Available from: http://clinicaltrials.gov/show/NCT00855335. Accessed June 26, 2013.

66. Clinical Trials.gov. Pharmacokinetic effects of new antiretroviral drugs on children, adolescents and young adults. Available from: http:// clinicaltrials.gov/show/NCT00977756. Accessed March 15, 2013.

67. Kakuda TN, Wade JR, Snoeck E, et al. Pharmacokinetics and pharmacodynamics of the non-nucleoside reverse transcriptase inhibitor etravirine in treatment-experienced HIV-1-infected patients. Clin Pharmacol Ther. 2010;88:695-703.
Pediatric Health, Medicine and Therapeutics

\section{Publish your work in this journal}

Pediatric Health, Medicine and Therapeutics is an international, peerreviewed, open access journal publishing original research, reports, editorials, reviews and commentaries. All aspects of health maintenance preventative measures and disease treatment interventions are addressed within the journal. Practitioners from all disciplines are invited to submit

\section{Dovepress}

their work as well as healthcare researchers and patient support groups. The manuscript management system is completely online and includes a very quick and fair peer-review system. Visit http://www.dovepress.com/ testimonials.php to read real quotes from published authors. 